\title{
Effect of Polymer Materials (Styrene- Butadiene-Styrene) on Marshall Asphalt Mix Criteria
}

\author{
Mohamed R. Elshahat, Alaa G. Sherif, Mohamed M. Elshafiey, Waleed F. Tawhed.
}

\begin{abstract}
: this research aims to identify the impact of using polymer materials on physical properties of traditional bitumen used in asphaltic mix based on Marshall Mix design proceedings.

During this research, traditional bitumen is modified by Styrene- Butadiene-Styrene (SBS). Percentages of 1,3,5,7, and 9\% of SBS by weight of bitumen were mixed. Physical tests such as Penetration Test, Viscosity Test, Softening Point Test, and Flash Point Test were carried out to evaluate the enhancement in the modified bitumen properties. After that, HMA is prepared with polymer modified bitumen to study the change in Marshall asphalt mix criteria. Results show that, using SBS as a modifier agent has a positive impact on the physical properties of traditional bitumen. According to these results, it can be said that the use of SBS polymers showed a significant and noticeable improvement in the performance of the asphalt mixture. Also, modified asphalt mix at any percentage of modifier agent recorded high improvement in stability than the conventional asphalt mix.
\end{abstract}

Keywords: Physical properties, SBS Polymer-Material, Marshall Asphalt Mix, Modified bitumen.

\section{INTRODUCTION}

P olymers are materials made of long repeating chains of molecules. Chain-shaped molecule whose rings are simple compound molecules (monomer) that are linked together by covalent bonds. there are two different sources to get polymers.

\section{A. Natural polymers}

Natural polymers are substances that can be extracted from vegetarian origin such as wood, cotton, natural rubber, Vegetarian glues or from animal origin such as wool, leather, hair,

Manuscript received on April 06, 2021.

Revised Manuscript received on April 15, 2021.

Manuscript published on April 30, 2021.

* Correspondence Author

Mohamed R. Elshahat*, Highway and Airport Engineering, Egyptian Russian University, Cairo, Egypt.

Alaa G. Sherif, Civil Engineering Department, Helwan University, Cairo, Egypt.

Mohamed M. Elshafiey, Highway and Airport Engineering, Egyptian Russian University, Cairo, Egypt

Waleed F. Tawhed, Civil Engineering Department, Helwan University, Cairo, Egypt.

(C) The Authors. Published by Blue Eyes Intelligence Engineering and Sciences Publication (BEIESP). This is an open access article under the CC BY-NC-ND license (http://creativecommons.org/licenses/by-nc-nd/4.0/) lint and silk, all of which are natural polymeric compounds necessary for our daily life. Among the foodstuffs that are considered natural polymers are starch, protein and cellulose.

\section{B. Synthetic polymers}

Synthetic polymers are materials that invaded the markets in the forties of the last century after the second world war, including plastics,

rubber, synthetic leather, nylons, protective coatings, and polyesters. In 1970, synthetic polymers were used as additives for traditional bitumen and determine their effect on the performance of asphaltic mix .

In 1975, several studies were conducted in the United States of America, it was found that polymers are widely used by $75 \%$ of researchers. Natural polymers are relatively complex and more expensive polymers compared to Synthetic polymers are categorized based on their chemical structure and natural characteristics.

Polymers are widely used in different proportions ranging from 4 to $6 \%$ by the weight of bitumen, as these ratios help improve the properties of bitumen in many ways, the most important of which is increasing the service life of the asphaltic mix and its temperature resistance. Polymers are less effective and more expensive if the ratio exceeds $6 \%$. Polymers can be divided into two main groups of plastomers (for instance, EVA, EMA, LLDPE, HDPE, PP, and PVC) and thermoplastic elastomers (e.g., SBS, SIS, SBR, and SEBS) [1].

There are four major categories of polymers, namely plastics, elastomers, fibers and coatings. In order to enhance bitumen characteristics, the polymer molecules combine with the bitumen molecules via chemical reactions, forming a new equilibrium system within the bitumen. The chemical composition of bitumen is the main factor affecting the accurate diffusion of polymer particles into bitumen, which in turn constitutes the main factor for the formation of the modified bitumen system[2].

Study the effect of Using SBS with percentages of 2, 4, and $6 \%$ by weight and $2 \%$ lime as mineral filler on different characteristics of asphaltic mix. The results showed a Significant improvement in both the stability, stiffness and the characteristic strength of the asphalt mixture. Based on maintained Marshall stability, adding just 2\% lime almost have the same impact as adding 6\% SBS. The use of lime in SBS modified blends results in a high degree of homogeneity and improved properties dramatically. Samples which contain $2 \%$ lime and $6 \%$ SBS, have higher stiffness modulus which is 2.3 times compared to the control mixture and showed the minimum

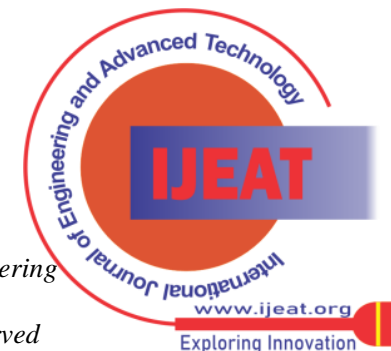


reduction in tensile strength ratio while maintaining 0.70 tensile strength ratio after seven freeze-thaw cycle [2].

To identify the asphaltic mix performance, control mixture, SBS modified asphalt mixture, and nano-montmorillonite (NMMT)/SBS composite modified asphalt mixture were designed and prepared. Marshall Tests were conducted and the results showed that NMMT/SBS modified asphalt shows the best mechanical performance and wetness sensitivity. This

show that NMMT/SBS composite material as an operative modifier can remarkable improve the characteristics of asphaltic mix [3].

many researches have conducted for identifying the physical properties of bitumen modified with polymers and the results showed that compared to Linear Low Density Polyetheylne (LLDPE) binder, the SBS modified bitumen has greater elastic recovery capacity.[4].

Different percentages of rubber crumbs were used as additives to the asphalt mixture and their effect on the physical properties of the asphalt mixture was studied. The results showed that the higher the percentage of rubber crumbs, the less the effect of aging on the physical properties of the modified bitumen with the rubber crumb. The results also showed a marked decrease in the degree of penetration and softening point[5].

The asphalt mixture is affected by the properties and behavior of the components. The most important of these components is the bitumen used in the asphalt mixture, which is negatively affected by the influence of surrounding environmental factors. Therefore, the use of additives is the best available way to improve the performance of the mixture. So, the objectives of this paper are:

1. Evaluate the performance of physical properties of SBS modified bitumen.

2. Study the effect of SBS Modified Bitumen on Marshall Mix design criteria

\section{EXPERIMENTAL PROGRAM}

Several tests have been conducted in order to study the influence of using SBS on the physical properties of modified bitumen. During this research, SBS were used with percentages (1\%, 3\%, 5\%, 7\% and $9 \%$ by weight of bitumen) to modify the bitumen used in the Asphaltic mix. Also, study the impact of using SBS on the physical properties of modified bitumen. Penetration test, softening point test, flash point test, and viscosity test are tests that performed to evaluate the improvements in the physical properties resulted in using SBS as bitumen modifier.

\section{A. Preparation of Modified Bitumen}

SBS materials with percentages of $(1,3,5,7$, and $9 \%$ by weight) used as additives as shown in Figure (1).

High shear mixer was used to disperse the additives particles into the bitumen homogenously as shown in Figure (2).

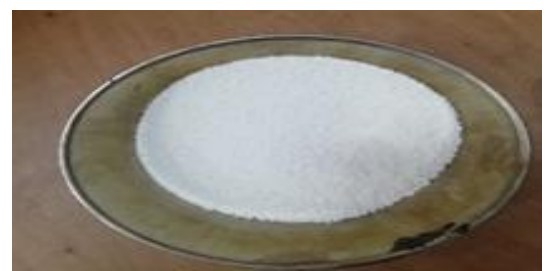

Figure (1): SBS Material.

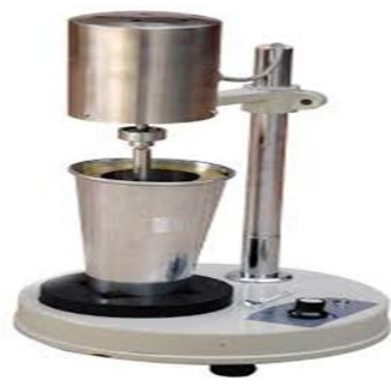

Figure (2): Mechanical Mixer.

The physical properties of modified bitumen can be inferred through many tests namely Penetration test (ASTM-D5 standard), flash point (ASTM-D3143-13 standard), softening point (ASTM-D36 standard), and viscosity (ASTM-D4402 standard) which carried out for modified bitumen specimens as shown in Figure (3) [23-26].

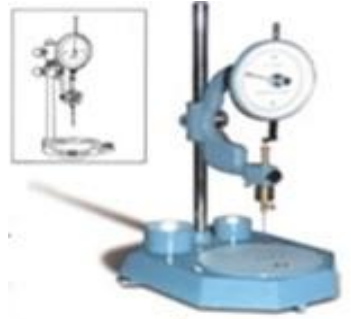

Penetration Test

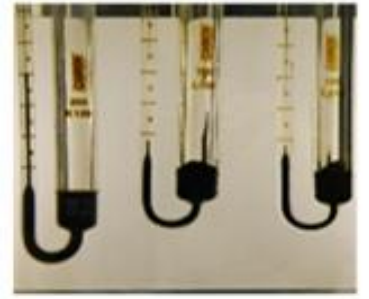

Viscosity Test

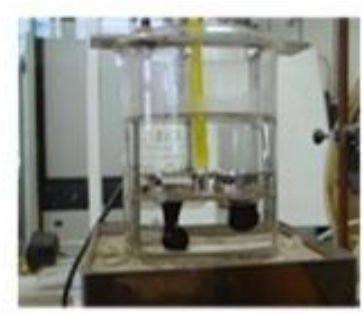

Softening Point

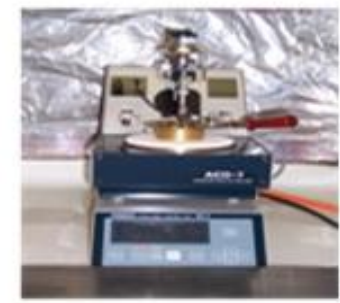

Flash Point

Figure (3): physical Properties of Bitumen.

Ten different Marshall Mix Designs were carried out for all mixtures \{i.e. five Marshall Mix design for SBS modified bitumen with percentages of $1,3,5,7$, and $9 \%$ \} as shown in table (1).

For all specimens, Marshall test (ASTM D5581 - 07a 2013) was carried out to determine the stability of the specimen versus the flow as shown in Figure (4), while Figure

(5) shows the preparation of

Marshall specimen.

Table- I: Marshall Mix design.

\begin{tabular}{|c|c|}
\hline Parameters & Mixing ratio \% \\
\hline Gravel 1 & $25 \%$ \\
\hline
\end{tabular}

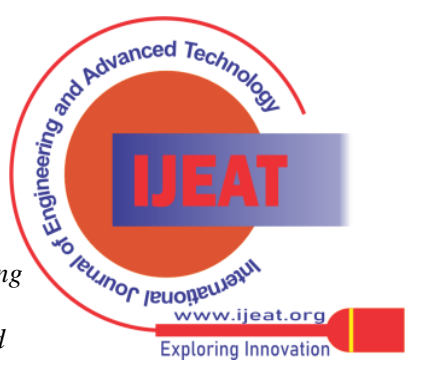




\begin{tabular}{|c|c|}
\hline Gravel 2 & $23 \%$ \\
\hline Sand & $45 \%$ \\
\hline Powder & $7 \%$ \\
\hline Bitumen content & $4,4.5,5,5.5$, and 6\% \\
\hline Kaolinite Nano-clay & $1,3,5,7$, and 9 \% \\
\hline SBS & $1,3,5,7$, and $9 \%$ \\
\hline
\end{tabular}

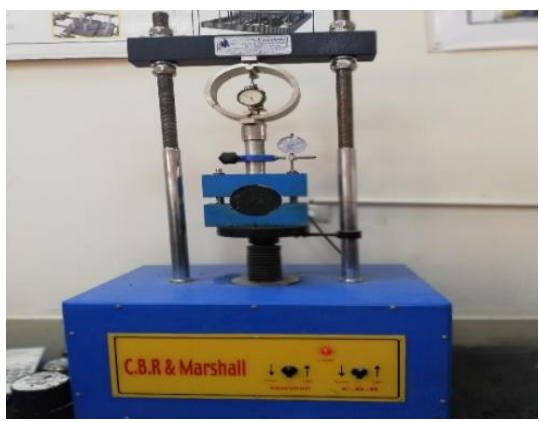

Figure (4): Marshall Test

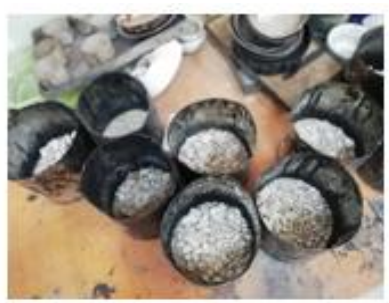

Mixing of each sample ingradients

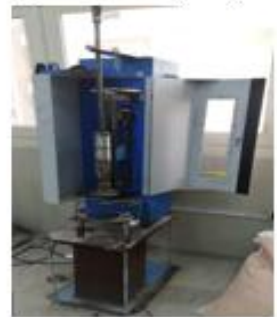

Marshall Compactor

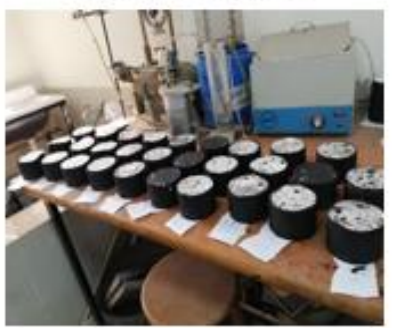

Cooling of samples

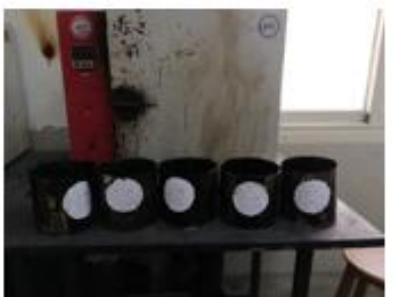

heating of samples

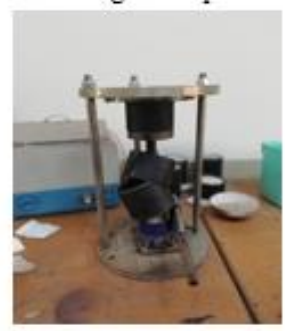

Getting Out sample

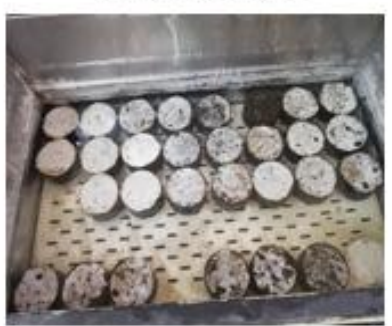

samples in Water Bath
Figure (5): preparation of Samples.

At last to achieve the optimum bitumen content, five relations were plotted with the bitumen content such as stability, flow, unit weight, air voids, and voids in mineral aggregate as shown in Figure (6). Optimum bitumen content, determined from the average of three bitumen content values (bitumen content at highest stability, bitumen content at highest unit weight, and bitumen content at $4 \%$ air voids), then, the average percentage must be checked against the limits of flow and voids in mineral aggregate as the limits of the Egyptian Code.
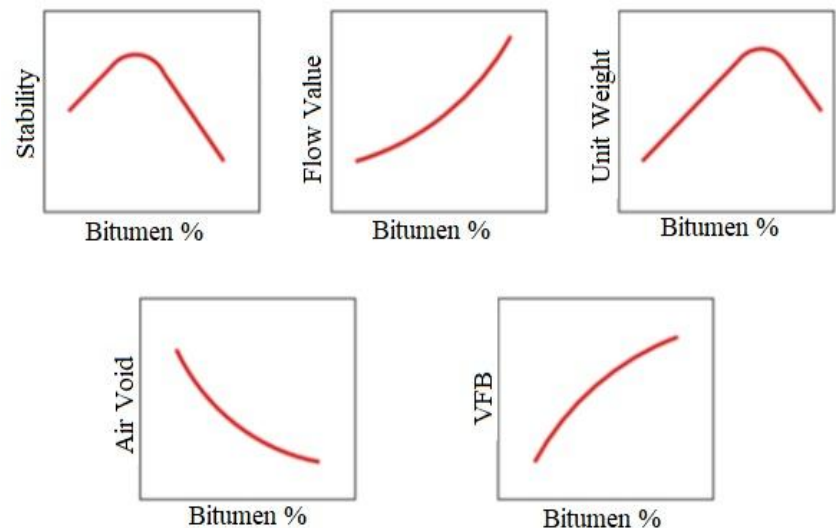

Figure (6): Marshall Mix Design Relations

\section{RESULTS AND ANALYSIS}

Based on the results obtained, it can be noted that physical properties of bitumen such as degree of penetration, softening point, flash point, and viscosity were improved as shown in Figures (7 to 10).

\section{A. Effect of SBS Modified Bitumen on physical Properties.}

Figure (7) show Penetration Behavior of modified bitumen samples. According to this figure, with the addition of SBS content, penetration decreased by $35 \%$. SBS changes the grade of bitumen. At $9 \%$ modifier, grade of bitumen changed from 60-70 to 40-50 in case of SBS modified bitumen.

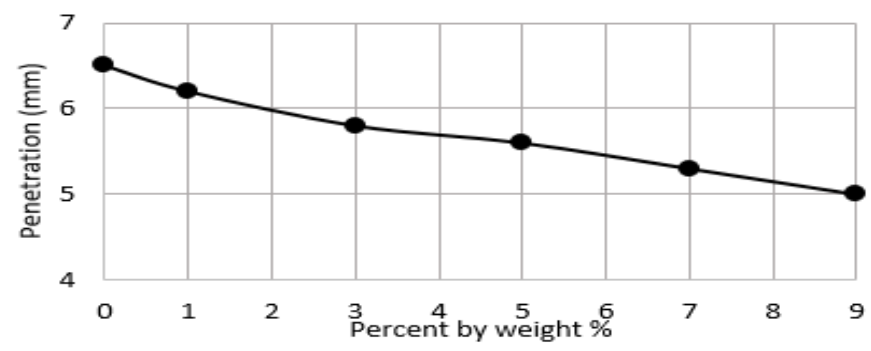

Figure (7): Penetration Behavior of SBS modified bitumen.

Figure (8) provide graphical description of Softening Behavior of modified bitumen samples. The analysis of results shows that modifier agents increase the softening point. At 9\% modifier agent's percentage, SBS increases softening by $55 \%$. The reason for that is the high melting temperature of SBS as a polymer material $160-200^{\circ} \mathrm{C}$.

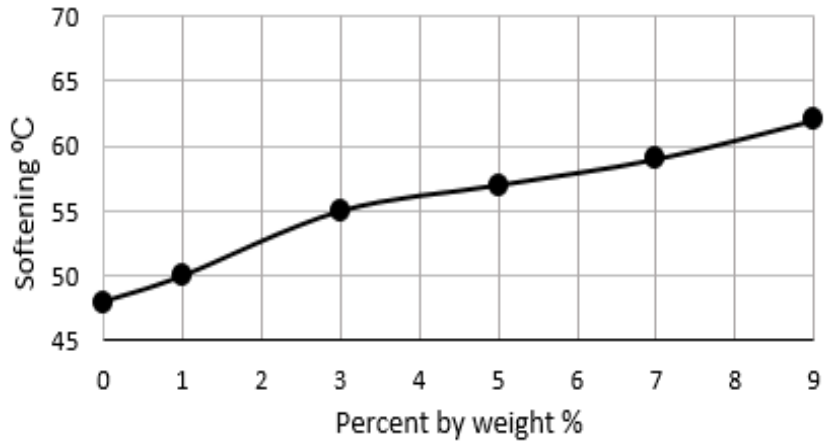

Figure (8): Softening Behavior of SBS modified bitumen.

Published By:

Blue Eyes Intelligence Engineering

\& Sciences Publication

DOI:10.35940/ijeat.D2415.0410421

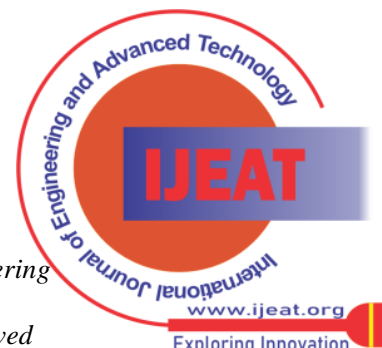


Flash Point Behavior of modified bitumen samples were computed and presented in figure (9). It can be observed that SBS improves the flash point. At $9 \%$, flash point increase by $5.5 \%$ for SBS.

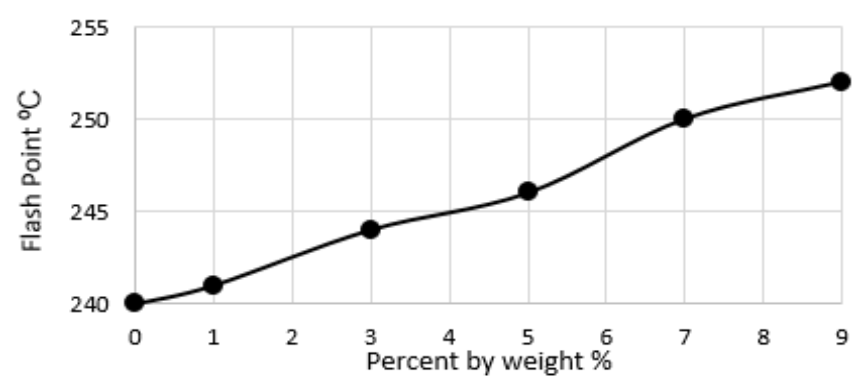

Figure (9): Flash Point Behavior of SBS modified bitumen.

From Figure (10), it's obvious that SBS modifier increase the viscosity. At $9 \%$, viscosity increased by $4 \%$. The reason of that may be the rough surface of SBS.

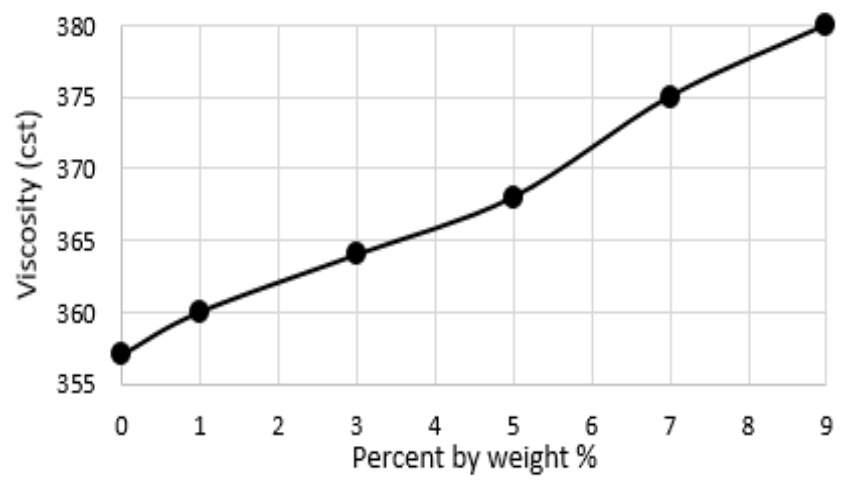

Figure (10): Viscosity Behavior of SBS modified bitumen

B. Effect of SBS Modified Bitumen on Marshall Mix design criteria.

During this stage, the influence of SBS modified bitumen on Marshall Mix design parameters (Unit Weight, VFB, Air Voids, Flow, Stability) was investigated and analyzed as indicated in Figures (11 to 20)

Figure (11) indicates the relation between different percentages of bitumen content $(4,4.5,5,5.5$, and 6\%) and unit weight for SBS Modified Bitumen. although SBS increases the unit weight by increasing the optimum bitumen content, SBS has a negative effect on unit weight. The maximum reduction is $2.3 \%$ for $9 \%$ SBS at $5.5 \%$ bitumen content.

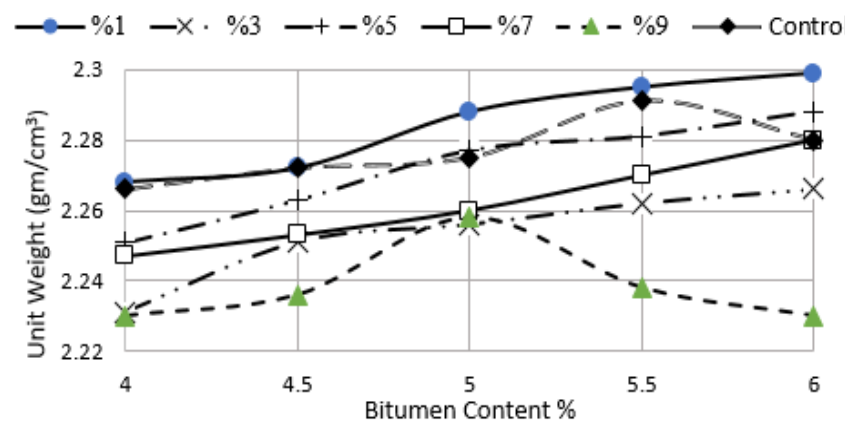

Figure (11): Unit Weight for SBS Modified Bitumen.

Figure (12) indicates the relation between bitumen content and the voids filled with bitumen (VFB) for SBS Modified Bitumen. The analysis of results shows that $1 \%$ SBS nearly has no effect on VFB. The other percentages decrease the. VFB at all bitumen contents. The reduction is nearly the same for all bitumen contents and it is about $9 \%$.

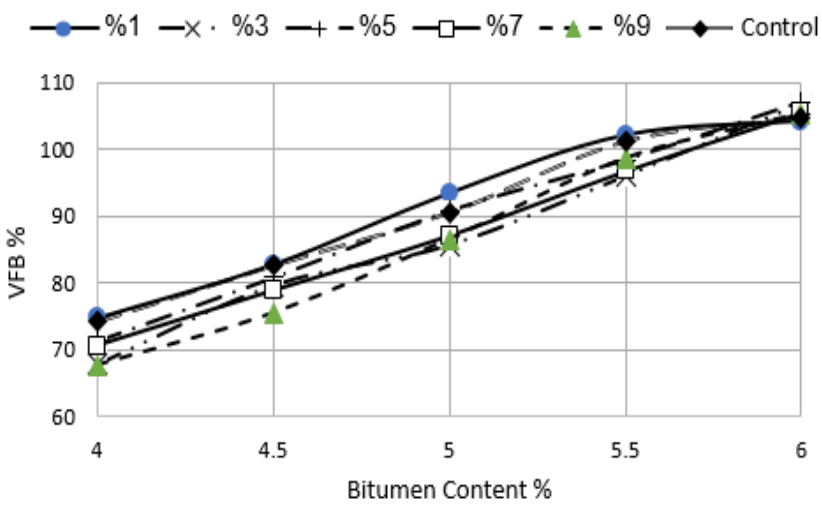

Figure (12): VFB for SBS Modified Bitumen.

Figure (13) show that using SBS increases the air voids compared to the conventional asphalt mix, although increasing the bitumen content decreases the air voids in their asphalt mixtures. The reason may be the roughness of modified bitumen, which causes difficulty spreading into voids.As shown in figure (14), the change of SBS percentage has no obvious effect on the flow of modified asphalt mix. The maximum increase in flow may be consider about 30\% and it occurred at $4 \%$ bitumen content.

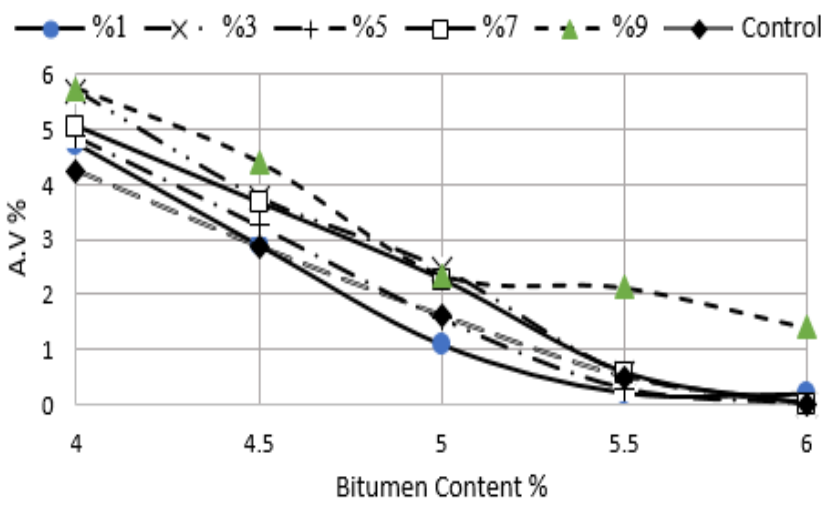

Figure (13): Air Voids for SBS Modified Bitumen

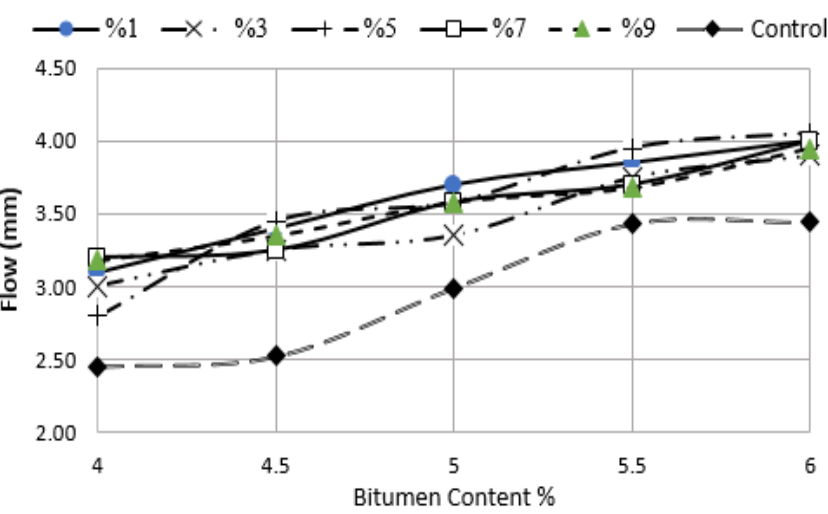

Figure (14): Flow for SBS Modified Bitumen

As shown in Figure (15) for SBS modified bitumen, increase in SBS up to 5\% increases the stability. After that percentage, stability is decreased. At $4.5 \%$ bitumen content, the stability increases by $85 \%$ for $5 \%$ SBS, $49 \%$ for $3 \%$ SBS, and $42 \%$ for $1 \%$ SBS.

Published By:

Blue Eyes Intelligence Engineering \& Sciences Publication (C) Copyright: All Rights Reserved

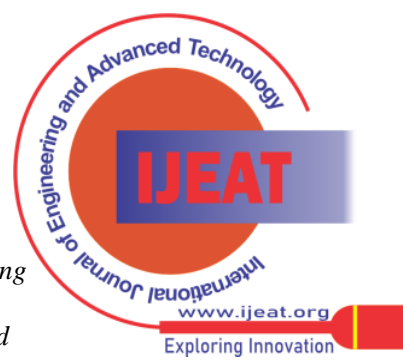




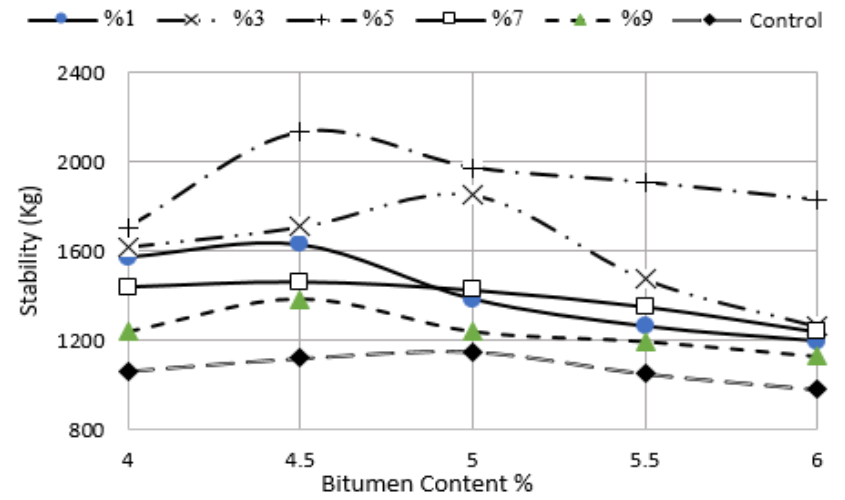

Figure (15): Stability for SBS Modified Bitumen

\section{CONCLUSION}

In this research SBS were used to modify bitumen with five different percentages $(1,3,5,7$, and $9 \%$ by weight). The physical properties were investigated before and after modified bitumen using SBS. The basic conclusions from this research can be drawn as follows:

1. results show that there is a Significant improvement in the physical properties of SBS modified bitumen compared to non-modified bitumen.

2. SBS at a content of $9 \%$ is record $35 \%$ lower penetration, increasing in softening by $55 \%$, flash point increase by $5.5 \%$, finally viscosity increased by $4 \%$ compared to reference sample.

3. SBS as a modifier has no significant influence on the unit weight, air voids, flow, and voids filled with bitumen.

4. Percentage from 1 to $7 \%$ for SBS increase the stability compared to the traditional mix.

\section{REFERENCES}

1. A. Behnood and M. Modiri Gharehveran, "Morphology, rheology, and physical properties of polymer-modified asphalt binders," Eur. Polymer. J., vol. 112, no. September 2018, pp. 766-791, 2019.

2. B. V. Kok and M. Yilmaz, "The effects of using lime and styrene-butadiene-styrene on moisture sensitivity resistance of hot mix asphalt," Construction Building Materials, vol. 23, no. 5, pp. 1999-2006, 2009.

3. X. Tang, X. Kong, F. Huang, and J. Li, "Performance evaluation of nano-montmorillonite/SBS modified asphalt paving mixtures," Materials Science Forum, vol. 688, pp. 191-194, 2011.

4. Ashok, T. Gupta, and S. K. Ravi, "Performance of Polymer Modified, Bitumen. Flexible Pavement "International Journal of Structural \& Civil Engineering Research, vol. 1, no. 1, pp. 1-10, 2012.

5. A. H. Ali, N. S. Mashaan, and M. R. Karim, "Investigations of physical and rheological properties of aged rubberised bitumen," Advances in Material Science \& Engineering, vol. 2013, pp. 1-8, 2013.

\section{AUTHORS PROFILE}

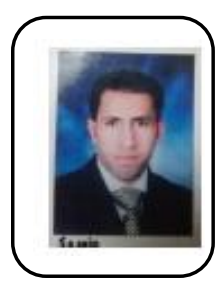

Mohamed R. Elshahat, is an Assistant Professor in Structural Department, Faculty of Engineering at Egyptian Russian University, Cairo, Egypt. He obtained his M.Sc. and Ph.D. from Helwan University, Egypt in 2009 and 2016 respectively. He is specialized in highway and airport. His research interests include; behavior and construction of concrete and pavement materials, strengthening of soil, in addition to studying innovative techniques for recycling organic materials to be used in soil and pavement.

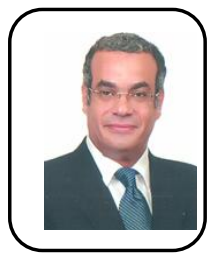

Alaa Sherif, ACI member is a Professor at the Civil Engineering Department, Helwan University, Mataria-Cairo, Egypt. He obtained his M.Sc. and Ph.D. from the University of Calgary, Canada in 1991 and 1996 respectively. He is a member of the Egyptian Code Higher Committee for Design of Reinforced Concrete Structures and an Associate Member of ACI-ASCE Committee 352, Joints and Connections in Monolithic Concrete Structures, Member of the Canadian Society for Civil Engineers CSCE and the International Association for Bridge Engineering IABSE. He holds several scientific awards such as the Canadian Gzowsky Medal and the Egyptian State Price. He is a fellow of the German Alexander von Humboldt Foundation. His main research interests include the design and serviceability of Reinforced Concrete Structures.

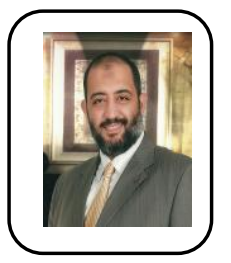

Waleed F. Tawhed, is an Associate Professor in Civil Engineering Department, Faculty of Engineering at Mataria, Helwan University, Cairo, Egypt. He has received his Ph.D. degree from the University of South Carolina, Columbia, USA in 2005. He is specialized in strength and properties of materials and Non-Destructive testing. His research interests include; behavior and construction of concrete and pavement materials, non-destructive evaluation and non-destructive testing of concrete and masonry materials, behavior and applications of modern composite materials in repair and strengthening of concrete structures, in addition to studying innovative techniques for recycling organic materials to be used in concrete structures. Dr. Tawhed is active in research and academic supervision on numerous engineering post-graduate students in the field of material science.

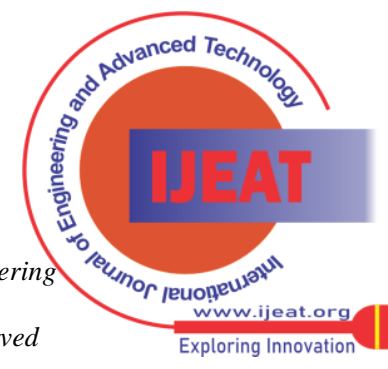

